\title{
PLANEJAMENTO E GESTÃO DA LOGÍSTICA REVERSA NO SETOR DE ENERGIA ELÉTRICA - UM ESTUDO DE CASO
}

\section{PLANNING AND MANAGEMENT OF REVERSE LOGISTICS IN THE ELECTRIC SECTOR - A CASE STUDY}

\author{
Frederico Pessanha Gomes ${ }^{1}$; Ubiratã Tortato ${ }^{2}$ \\ ${ }^{1}$ Pontíficia Universidade Católica do Paraná - PUCPR - Curitiba - Brasil \\ frederico.gomes@uol.com.br \\ ${ }^{2}$ Pontíficia Universidade Católica do Paraná - PUCPR - Curitiba - Brasil \\ ubirata.tortato@pucpr.br
}

\begin{abstract}
Resumo
Este estudo verifica práticas de planejamento e gestão da logística reversa na viabilização de um projeto de troca de geladeiras antigas, com baixa eficiência energética, por novas, que refrigeram melhor consumindo menos energia elétrica. Com o intuito de acompanhar os processos de logística reversa e confrontar a prática observada com a teoria, foi utilizado o método de pesquisa exploratória na forma de estudo de caso. A coleta de dados foi realizada por meio de duas fontes principais de evidência: entrevista semi-estruturada e análise de documentos. Como principal resultado conclui-se que o planejamento e gestão dos processos de logística reversa, estão aderentes a teoria preconizada pela literatura, proporcionando vantagens competitivas para a organização em termos financeiros, como também fortalecendo sua imagem corporativa junto aos clientes e à comunidade a realizar um projeto que contribui para o desenvolvimento sustentável.
\end{abstract}

Palavras-chave: logística reversa, sustentabilidade, estratégia, eficiência energética.

\section{Introdução}

Durante as últimas décadas pode-se verificar um significativo aumento da preocupação da sociedade com a necessidade de se buscar um equilíbrio entre desenvolvimento econômico, preservação do meio ambiente e justiça social. Neste cenário, coloca-se em questão o papel das organizações no contexto humano e social, apoiando alternativas conceituais de gestão mais amplas e que reconheçam a importância estratégica de estar alinhadas aos interesses dos principais stakeholders, ou seja, das partes interessadas que afetam ou são afetadas pelo alcance dos objetivos da empresa (FREEMAN, 1984).

É crescente a valorização das questões ambientais no segmento empresarial, preocupando-se em atender às novas exigências regulatórias impostas pelo mercado e pela sociedade como um todo. 
O foco restrito nos aspectos econômicos, que antes praticamente monopolizava o processo de planejamento, tem sido complementado por um conceito mais abrangente de sustentabilidade empresarial, em que os objetivos financeiros são congruentes às iniciativas de redução dos impactos indesejáveis ao meio ambiente (STROBEL et al., 2004).

Atendendo a essa necessidade, organizações de todo o mundo têm demonstrado publicamente quais são suas diretrizes e propósitos de sustentabilidade empresarial de longo prazo com o objetivo de se perpetuar, contribuir para o desenvolvimento da sociedade e reduzir os impactos causados por suas atividades, colaborando assim com a construção de uma sociedade mais sustentável.

Ações com objetivo de preservar o meio ambiente, antes realizadas isoladamente, hoje já são mais comuns e frequentes. A conscientização da sociedade tem obrigado as organizações a incorporar padrões que sejam compatíveis com a sustentabilidade ambiental, com vistas a colaborar para a diminuição da poluição e para minimizar os impactos nos recursos naturais, cada vez mais escassos. Esse processo de conscientização da sociedade implica no desenvolvimento de uma legislação coerente com as formas de produção e consumo sustentáveis, que objetivam minimizar os impactos das atividades produtivas no meio ambiente.

Suportando esses objetivos, a logística vem despertando um interesse crescente nas organizações empresariais, bem como nas pesquisas científicas, uma vez que pode ser considerada uma ferramenta capaz de gerar vantagens competitivas para as organizações, bem como contribuir para a sustentabilidade empresarial e ambiental. Nesse sentido, as recentes regulamentações ambientais vêm obrigando aos planejadores logísticos incluir os custos e benefícios indiretos da produção sustentável.

De forma complementar, novas tecnologias em conjunto com as necessidades impostas pelo mercado fez com que o conceito amplo de logística se especializasse para atender a necessidade crescente de ferramentas de gestão eficientes ao fluxo de retorno de produtos e materiais. Além deste aumento da eficiência e da competitividade das empresas, o governo, por meio da legislação, e a mudança na cultura de consumo, por parte dos clientes, também tem incentivado a logística reversa.

Esses processos logísticos reversos também contribuem por meio do gerenciamento de resíduos, da reciclagem, do reuso e da recuperação, na diminuição do uso de recursos não renováveis e para a redução ou eliminação de resíduos que afetam negativamente o meio ambiente (CARTER; ELLRAM, 1998).

Aprofundando essa abordagem, e de acordo com Leite (2003), a logística reversa se destaca como uma área de pesquisa da logística empresarial que planeja, operacionaliza e controla o processo e as informações logísticas correspondentes do retorno dos bens de pós-venda e de pós- 
consumo ao ciclo produtivo, por meio dos canais reversos de distribuição, agregando-lhes desta forma valor de diversas naturezas: econômico, ambiental, social, entre outros.

As iniciativas de logística reversa têm deixado de ser apenas contabilizadas como custos obrigatórios às organizações, impostos pela regulamentação, passando a ser percebidos como uma vantagem competitiva, pois, utilizando-se dela consegue-se aprimorar o relacionamento com os demais agentes da cadeia produtiva, com o mercado e com os clientes (STOCK et al., 2002). Sendo que algumas iniciativas podem até gerar um benefício econômico adicional para a organização, como é o caso da empresa que é apresentada neste estudo de caso.

Mesmo sendo notável o potencial da logística reversa na economia e na sustentabilidade ambiental, a falta de planejamento, informação e consequente estrutura dos canais de distribuição reversos podem comprometer seu funcionamento de forma eficiente. Este estudo, assim, procura verificar empiricamente a utilização da logística reversa no processo de troca de geladeiras antigas, com baixa eficiência energética, por novas, que refrigeram melhor consumindo menos energia elétrica, por meio de um estudo de caso único na Copel - Companhia Paranaense de Energia.

Esse projeto da Copel faz parte do Programa de Eficiência Energética que é um compromisso legal que todas as empresas de distribuição de eletricidade do país têm com a Agência Nacional de Energia Elétrica (Aneel). Elas devem destinar o equivalente a 0,5\% da sua receita anual para custear programas, ações e projetos previamente aprovados e homologados pela Aneel que estimulem e ampliem a eficiência do uso da energia elétrica pelo consumidor final. Nesse sentido, os programas de eficiência energética que têm por objetivo reduzir o consumo de energia elétrica podem trazer vários benefícios para a sociedade e também para as concessionárias.

Complementarmente, este estudo tem também o objetivo de verificar a contribuição estratégica da logística reversa na redução da necessidade de investimentos em geração e transmissão de energia, bem como, dos seus benefícios para a sustentabilidade ambiental e social. Isso porque percebesse que existe um escasso referencial bibliográfico acerca do tema, o que dificulta a obtenção de informações e uma visão mais abrangente e didática sobre este assunto.

Dessa forma, a escolha do tema se justifica pela necessidade de pesquisas nesta área e busca enriquecer o debate atual acerca da relação entre estratégia empresarial, sustentabilidade e logística reversa, por meio de um estudo de caso, com intuito de entender melhor essa relação. Nesse sentindo, estabeleceu-se como problema de pesquisa, verificar como os processos de logística reversa estão implantados no contexto do Programa de Eficiência Energética da Copel.

Este estudo vai ser inicialmente desenvolvido a partir da revisão da literatura referente aos conceitos de sustentabilidade empresarial, logística e logística reversa, bem como de sua função estratégica como viabilizadora de uma maior eficiência econômica e de sustentabilidade ambiental. Em seguida, irá apresentar a metodologia utilizada, e os resultados empíricos encontrados. Por fim, 
apresentará as conclusões e recomendações de estudos futuros.

\section{Referencial teórico}

Neste capítulo será abordado um conjunto de conceitos relevantes no tocante à compreensão da relação entre a adoção de práticas de sustentabilidade, logística reversa e sua função viabilizadora de estratégias empresariais.

\subsection{Sustentabilidade empresarial e eficiência econômica}

A expressão sustentabilidade empresarial pode ser considerada, de maneira abrangente, como sendo sinônima de desenvolvimento empresarial sustentável, o qual tem como principal objetivo atender as necessidades atuais sem comprometer possibilidades das gerações futuras satisfazerem às suas próprias necessidades (CMMAD, 1991).

Mais especificamente, a sustentabilidade empresarial também pode ser encarada como uma função estratégica, pois endereça aspectos como busca de longevidade, sucesso de longo prazo e comprometimento com os públicos estratégicos da empresa; adicionalmente o conceito de sustentabilidade empresarial reconhece e abrange aspectos econômicos, sociais e ambientais.

Segundo esse entendimento, as empresas devem prestar contas, não só aos acionistas e a credores, mas também a seus stakeholders (FREEMAN, 1984). Os stakeholders estão presentes em qualquer parte do mundo e fazem suas reivindicações por meio da imprensa tradicional, e também por meio dos novos veículos que possibilitam a interatividade, como é o caso da Internet (SAVITZ; WEBER, 2007).

Sendo relativamente recente, o conceito de sustentabilidade ainda não está completamente consolidado. Ainda não existe consenso em relação a sua definição e à sua aplicabilidade, sendo que no mundo empresarial também o mesmo se encontra em fase de construção e adaptação. Sabese, no entanto, que na perspectiva da sustentabilidade empresarial os resultados financeiros não são os únicos e nem mesmo os mais importantes critérios de avaliação do sucesso das organizações. Os impactos econômicos, sociais e ambientais tornam-se informações de suma importância a todos os seus stakeholders.

Neste contexto são discutidas as ações de responsabilidade social corporativa (RSC) realizadas pelas empresas. Segundo Carrol (1979) a RSC são as expectativas econômicas, legais, éticas e discricionárias que a sociedade possui em relação às empresas em determinado período de tempo. Desta forma, o desenvolvimento sustentável, com foco na sustentabilidade empresarial, pode oferecer inúmeras oportunidades de novos negócios que propiciem ao mesmo tempo 
viabilidade econômica e ganhos sócio-ambientais.

Embora o tema ainda sugira uma mudança de paradigma, não se espera que esta ocorra rapidamente. Ao contrário, trata-se muito mais de um processo de longo prazo em que as organizações incorporarão mecanismos em suas estratégias de acordo com seus recursos disponíveis e as demandas da sociedade em geral. Antes da década de 1990, desempenho econômico e preservação do meio ambiente eram vistos como conceitos antagônicos e de difícil conciliação. A partir da década 1990 passaram a ganhar mais visibilidade no mundo empresarial, idéias de que os investimentos ambientais não necessariamente atrapalham sua competitividade, podendo, ao contrário, potencializá-la. É nessa perspectiva de contribuição para a eficiência econômica e sustentabilidade ambiental, que se enquadram os processos de negócio denominados de logística reversa.

\subsection{A logística reversa}

Considerando-se uma perspectiva macroeconômica a logística pode ser entendida como o processo responsável pelo fluxo físico dos materiais no setor industrial, passando pelos vários elos dos canais de distribuição (BOWERSOX; CLOSS, 2001). Nas organizações o termo é utilizado na descrição das atividades relacionadas com os fluxos de entrada de suprimentos e de saída de produtos e tende a ganhar uma visão integrada entre as empresas à medida que estas planejam suas atividades de forma conjunta, ganhando em eficiência e eficácia.

Para Ballou (2007), a logística busca otimizar os fluxos de informações e materiais desde o ponto de origem (aquisição) até o ponto de destino final (consumidor), visando assim proporcionar níveis de serviço adequados as necessidades dos clientes/fornecedores e a um custo competitivo. Nesse sentido, vários fluxos como: previsão de demanda, aquisição de suprimentos, serviço ao cliente, processamento de pedidos, embalagem, transporte, distribuição, controle de inventário, armazenagem e estocagem, localização da unidade fabril e depósitos, movimentação de materiais e peças de reposição, serviços ao cliente, reaproveitamento e remoção de sucata e gestão de devoluções, são considerados como parte da administração logística em uma organização (LAMBERT, 1998).

Porém, em uma perspectiva mais atual e completa, pode-se considerar que a logística tradicional faz parte de um conceito mais amplo de Supply Chain Management (SCM). A SCM trata da integração holística dos processos de negócios abrangendo a gestão de toda a cadeia produtiva de uma forma estratégica e integrada, abrangendo dessa forma a logística tradicional e também o conceito de logística reversa. 
Segundo o Council of Supply Chain Management Professionals (CSCMP, 2010), "a logística reversa é um segmento especializado da logística que enfoca a movimentação e gestão dos produtos e dos recursos após a venda e após a entrega ao cliente. Inclui devoluções de produtos para reparação e / ou crédito". Desde então, as definições de logística foram abrangendo novas áreas de atuação incluindo todas as formas de movimentos de produtos e informações até o gerenciamento dos canais reversos.

Leite (2003) define a logística reversa como:

[...] a área da logística empresarial que planeja, opera e controla o fluxo e as informações logísticas correspondentes, do retorno dos bens de pós-venda e de pósconsumo ao ciclo de negócios ou ao ciclo produtivo, por meio dos canais de distribuição reversos, agregando-lhes valor de diversas naturezas: econômico, legal, logístico, de imagem corporativa, entre outros.

Em consonância com esse conceito, os materiais podem retornar ao produtor ou podem ser recolocados a venda se ainda estiverem em condições adequadas de comercialização. Além disso, os bens podem ser reciclados ou recondicionados. O enfoque de atuação da logística reversa envolve então a reintrodução dos produtos ou materiais à cadeia de valor por meio do ciclo produtivo ou de negócios e, portanto, a intenção é que um produto só seja descartado em último caso. Dessa forma, por meio da gestão do fluxo reverso de produtos a logística reversa integra os canais de distribuição reversos.

Quanto à classificação dos canais de distribuição reversos, têm-se que o canal de distribuição reverso de pós-consumo se caracteriza por produtos oriundos de descarte após uso e, desta forma, que pode ser reaproveitado ou descartado. Já o canal de distribuição reverso de pósvenda é caracterizado pelo retorno de produtos com pouco ou sem nenhum uso que apresentaram problemas que podem ser considerados de responsabilidade do fabricante ou distribuidor e, ainda, por insatisfação do consumidor. Porém, ainda nesse sentido, cabe ressaltar que existem diversos outros motivos para que um produto retorne pela cadeia de suprimentos, tais como: defeito, falta de atendimento às expectativas, erro de pedidos, excesso de estoque, danificação ou contaminação do produto e produtos fora de linha.

Da mesma forma que a logística reversa de pós-venda, a atividade logística relacionada ao pós-consumo também possui um objetivo econômico. De acordo com Leite (2003), o objetivo econômico de implantação da logística reversa de pós-consumo se deve às economias relacionadas com o aproveitamento das matérias-primas secundárias ou provenientes de reciclagem bem como da revalorização dos bens por meio da reutilização e reprocesso.

Além do objetivo econômico, diferentemente do canal de pós-venda, o retorno de bens usados ocorre muito mais por questões ambientais e legais que pela possibilidade de retornar o bem 
à cadeia de valor. Assim sendo, esta atividade é mais intensa em locais onde existe uma maior pressão da sociedade e/ou que a legislação e fiscalização são mais rígidas.

Existem outras motivações estratégicas para que as empresas operem os canais reversos, além do já citado ganho econômico, como por exemplo, o aumento da competitividade, a limpeza dos canais (estoques), respeito à legislação e a recuperação de ativos (ROGERS; TIBBENLEMBKE, 1998).

O processo logístico reverso pode ser tratado com diferentes enfoques pelas organizações: para algumas os programas de logística reversa traz benefícios como a redução de custos, enquanto que para outras pode trazer problemas operacionais ou de aumento de custos (MALINVERNI, 2002).

\subsection{A logística reversa e sua função estratégica}

As demandas do mercado e a evolução da sociedade têm exigido das organizações um esforço com objetivo de aumentar sua competitividade para se manter nos negócios. Neste sentido, atividades que reforcem alguma vantagem competitiva para as organizações ganham destaque devido à sua importância no estabelecimento de relacionamento com seus stakeholders. A logística reversa se destaca como uma destas atividades. Nesse sentido, deve ser mais bem compreendida e pode ser utilizada estrategicamente por fornecer oportunidades que, muitas vezes, são complementares e propiciam vantagens estratégicas. De acordo com Chaves e Martins (2005), dentre essas se podem citar:

- Atendimento às demandas ambientais: A conscientização sobre a sustentabilidade é uma realidade e deve provocar uma reorientação da produção e do consumo para o crescimento sustentável. Nesse contexto, a logística tem a função estratégica de minimizar o impacto ambiental, não só dos eventuais resíduos provenientes das etapas de produção e do pós-consumo, mas também dos impactos ao longo do ciclo de vida dos produtos.

- Redução de custos e necessidade de novos investimentos: O eventual reaproveitamento ou troca de materiais e a economia com embalagens retornáveis fornecem ganhos que estimulam novas iniciativas e esforços em desenvolvimento e melhoria dos processos de logística reversa.

- Motivações competitivas: Uma possibilidade de se conseguir vantagem competitiva é a garantia de políticas de retorno de produtos que ajudem na fidelização dos clientes. Nesse sentido, empresas que possuem um processo de logística reversa bem estruturado e gerido, apresentam maiores chances de sobressair no mercado, pois estão melhor capacitados para atender aos seus clientes, isto é, ganham competitividade por fornecerem um serviço de valor reconhecido pelo cliente. 
- Construção de uma imagem corporativa positiva: Várias empresas estão utilizando logística reversa estrategicamente e se posicionando como empresa cidadã, contribuindo com a comunidade e ajudando as pessoas menos favorecidas. Com isso, as empresas conseguem um aumento do valor da marca e muitas vezes de seus produtos também. Estas políticas podem não ser a razão pela qual todos os clientes compram seus produtos ou consomem seus serviços, mas elas são consideradas um forte incentivo de marketing.

- Melhoria no nível de serviço oferecido ao cliente: A logística reversa é uma estratégia para agregar valor ao produto de várias formas, desde fornecer uma ferramenta de apoio ao marketing de relacionamento com o consumidor após a compra até oferecer um serviço orientado para a preservação ambiental. Esta elevação no nível de serviço deve ser no sentido de desenvolver uma vantagem competitiva sustentável para as empresas, visto que as melhorias introduzidas no serviço ao cliente de uma empresa não são facilmente copiadas pelos competidores como o são as mudanças no produto, no preço e na promoção.

\subsection{Eficiência energética}

Atualmente, em nossa sociedade, a realização de praticamente qualquer atividade só é possível com o uso intensivo de uma ou mais formas de energia. A energia é usada em equipamentos relativamente simples como lâmpadas e motores elétricos, bem como em sistemas mais complexos que encerram diversos outros equipamentos como é o caso das geladeiras, automóveis ou mesmo de uma unidade fabril. Durante seu funcionamento, estes equipamentos e sistemas transformam formas de energia, sendo que uma parte dessa energia sempre é perdida para o meio ambiente durante esse processo.

Tangibilizando tal conceito, pode-se citar o exemplo de uma lâmpada incandescente comum que tem uma eficiência de $8 \%$. Ou seja, $8 \%$ da energia elétrica usada é transformada em luz e o restante aquece o meio ambiente (INEE, 2001). Ainda de acordo com o mesmo instituto, a eficiência energética é uma atividade que procura otimizar o uso das fontes de energia. A utilização racional de energia, às vezes chamada simplesmente de eficiência energética, consiste em usar menos energia para fornecer a mesma quantidade de valor energético.

É importante entender que a eficiência energética não é o racionamento nem a racionalização forçada, que tem por objetivo a redução do serviço energético em vez da redução da energia para o mesmo serviço. A eficiência energética também não é a limitação da demanda de potência, apesar desta ser muitas vezes uma consequência direta de reduzir o consumo ou um elemento complementar em programas de otimização elétrica. 
Melhorar a eficiência significa reduzir o consumo de energia primária necessário para produzir um determinado serviço de energia. A redução pode acontecer em qualquer etapa da cadeia das transformações. Pode também ocorrer devido à substituição de uma forma de energia por outra no uso final. Historicamente, a substituição de combustíveis por eletricidade resultava muitas vezes em reduções de energia primária. No Brasil, hoje, a substituição da eletricidade pelo gás natural em alguns processos térmicos pode reduzir a energia primária necessária.

Um fator crítico na evolução futura do consumo energético será a eficiência dos novos eletrodomésticos vendidos e seu uso adequado. Os potenciais de redução do consumo específico de alguns tipos de eletrodomésticos são significativos. A produção da grande maioria dos eletrodomésticos hoje é feita por empresas multinacionais, o que deve facilitar a transferência de pelo menos parte dos ganhos de eficiência conseguidos no exterior para Brasil. Neste mercado de produtos de massa, porém, a experiência tem mostrado que é importante haver uma ação política sempre presente, como ocorre nos Estados Unidos e tem sido observado no Brasil com a ação do PROCEL (Programa Nacional de Conservação de Energia Elétrica).

Assim sendo, posto que o refrigerador elétrico é responsável por aproximadamente um terço do consumo residencial, pode-se obter um ganho expressivo em termos de redução de demanda a partir da adoção de equipamentos mais eficientes (INEE, 2001). No setor residencial a substituição de refrigeradores antigos por modelos eficientes pode gerar, segundo o PROCEL, uma economia de eletricidade entre 30 e 40\%. De acordo com um estudo de caso conduzido por Jannuzzi et al. (2002), a substituição de refrigeradores nacionais, num período entre 2005 e 2020, seria capaz de gerar uma economia de $43 \%$ no uso de eletricidade, com um tempo de retorno de 7 anos e uma economia nacional acumulada de 80 TWh.

Aprofundando a perspectiva social, os consumidores de baixa renda representam um desafio especial. Geralmente são introduzidos no mercado consumidor via equipamentos ineficientes. Muitos compram equipamentos de segunda mão. Ao comprar equipamentos novos, buscam os mais baratos ou os com melhor financiamento. Assim, os consumidores de baixa renda acabam sendo consumidores bem mais intensivos de energia por unidade de serviço energético. O impacto sobre orçamentos familiares pode ser substancial. Programas de eficiência podem diminuir o impacto.

Consideráveis avanços na promoção da eficiência energética estão sendo feitos no Brasil. Mais recentemente, seguindo o exemplo de muitos países o Brasil tem criado mecanismos para financiar atividades de interesse público (Jannuzzi, 2000, Wiser; Murray et al., 2003), garantindo fundos para investimento em eficiência energética, pesquisa e desenvolvimento. Companhias de distribuição de eletricidade são obrigadas a investir parte de sua receita anual em programas de eficiência energética sob a supervisão do órgão regulador (Aneel). Por outro lado, desde 1994 o selo PROCEL estimula indiretamente os fabricantes a disponibilizar no mercado equipamentos 
eficientes.

Nesse contexto, os programas de substituição de refrigeradores das concessionárias que focalizam a população de baixa renda apresentam-se como alternativa de iniciativas nesse sentido.

\section{Metodologia}

Com o intuito de identificar as práticas de logística reversa no processo e confrontar a prática observada com a teoria sobre esse assunto, optou-se pelo método de pesquisa exploratória na forma de estudo de caso único na empresa Copel - Companhia Paranaense de Energia.

\subsection{O estudo de caso}

Segundo Yin (2005), o estudo de caso é utilizado nas situações em que se colocam questões do tipo "como" e "por que", quando o pesquisador tem pouco controle sobre os acontecimentos e quando o foco se encontra em fenômenos contemporâneos inseridos em algum contexto da vida real. Sendo que existem seis fontes de evidências que podem ser usadas em estudo de caso: entrevistas, registros em arquivo, pesquisa documental, observação direta e participante.

Nesse sentido, considerando o que diz Yin (2005), a presente pesquisa se enquadra na classificação de estudo de caso, pois se quer determinar 'como' os conceitos de logística reversa estão sendo utilizados na empresa em questão.

\subsection{Coleta e análise de dados}

Neste estudo a coleta de dados foi obtida por meio de duas fontes de evidência: entrevista semi-estruturada e análise da documentação da empresa. A entrevista semi-estruturada foi realizada com a coordenação de marketing da empresa, abordando os aspectos referentes aos objetivos gerais do programa, seu público alvo, motivadores, regulamentação, processos operacionais de logística, entre outros itens. O levantamento bibliográfico partiu da análise de artigos anteriormente publicados sobre o tema, sítio da empresa e da agência reguladora (Aneel) e matérias jornalísticas na imprensa, que possibilitaram a identificação do processo de logística reversa vigente na empresa.

Para identificar e interpretar os dados coletados foi utilizada à técnica de análise de conteúdo, que, conforme Bardin (1997), é a técnica mais indicada para a análise de comunicações, sejam elas escritas ou orais.

Dado esse contexto, estabeleceu-se como problema de pesquisa, identificar como os processos de logística reversa estão implantados no contexto do Programa de Eficiência Energética 
da Copel, que visa à troca de geladeiras antigas, com baixa eficiência energética, por novas, que refrigeram melhor consumindo menos energia elétrica.

$\mathrm{Na}$ sequência, serão apresentados a empresa objeto do estudo, seu programa de eficiência energética e os resultados da análise de conteúdo, bem como as conclusões decorrentes de tal análise.

\section{Apresentação e análise dos resultados}

\subsection{A Companhia Paranaense de Energia, Copel}

Neste momento, cabe realizar a apresentação da Companhia Paranaense de Energia, COPEL, por ter sido a empresa onde foi realizado o estudo de caso deste trabalho. Em seu sítio na internet, a COPEL (2009) dá detalhes sobre sua história e alguns dados sobre a companhia:

A COPEL é a maior empresa do estado do Paraná e foi criada em 26 de outubro de 1954 com controle acionário do governo do Estado. Ela abriu seu capital ao mercado de ações em abril de 1994 e tornou-se, em julho de 1997, a primeira empresa do setor elétrico brasileiro, listada na Bolsa de Valores de Nova Iorque. Também está presente, desde junho de 2002, na Comunidade Econômica Européia, na Latibex, o braço latino-americano da Bolsa de Valores de Madri. A partir do dia 7 de maio de 2008, as ações da COPEL passaram para o nível 1 de Governança Corporativa da Bolsa de Valores de São Paulo (Bovespa).

A Companhia atende diretamente a 3.455 .760 unidades consumidoras em 393 municípios e 1.118 localidades (distritos, vilas e povoados) paranaenses. Os consumidores são divididos em 2,7 milhões residenciais, 60 mil industriais, 289 mil comerciais e 335 mil rurais. O quadro de pessoal é integrado por 8.100 empregados.

A COPEL possui quatro áreas específicas de atuação: geração, transmissão e distribuição de energia elétrica e serviços de telecomunicações. Cada área corresponde a uma diretoria específica da empresa e se relaciona com as demais para o atendimento da comunidade paranaense.

\subsection{O programa de eficiência energética da Copel}

O Programa de Eficiência Energética da Copel é executado anualmente em atendimento à cláusula do Contrato de Concessão de Distribuição de Energia Elétrica e à Lei no 9.991/00.

A legislação aplicável à matéria determina que as concessionárias e permissionárias de serviços públicos de distribuição de energia elétrica devam aplicar parte de sua receita operacional líquida anual em programas de eficiência energética no uso final, isto é, em projetos executados em 
instalações de clientes e/ou que proporcionem benefícios para o cliente. Os critérios para aplicação dos recursos e procedimentos necessários para apresentação do Programa à Aneel estão estabelecidos na Resolução Aneel no 300/2008.

De acordo com o manual para elaboração do programa de eficiência energética da Aneel, os projetos que envolvem substituição de equipamentos de baixa eficiência por equipamentos mais eficientes, todos os equipamentos retirados de operação devem ser descartados. Esse processo deve ser extremamente criterioso e todas as regras estabelecidas pelo Conselho Nacional do Meio Ambiente - CONAMA devem ser seguidas. Sendo que no descarte de equipamentos de refrigeração, deverá ser feito o recolhimento do fluido refrigerante, conforme resolução CONAMA $\mathrm{n}^{\mathrm{o}} 267$, de 14 de setembro de 2000 .

Em caso de impedimento de retirar os equipamentos antigos, a concessionária/permissionária deverá garantir por meio de cláusula contratual que os equipamentos antigos não poderão retornar ao uso e serão descartados pela empresa beneficiada pelo projeto, de acordo com as condições supracitadas.

O Programa de Eficiência Energética é, portanto, um compromisso legal que todas as empresas de distribuição de eletricidade do país têm com a Aneel. Elas devem destinar o equivalente a $0,5 \%$ da sua receita anual para custear programas, ações e projetos previamente aprovados e homologados pela Aneel que estimulem e ampliem a eficiência do uso da energia elétrica pelo consumidor final.

$\mathrm{Na}$ perspectiva da Copel "incentivar o uso eficiente da eletricidade é a forma mais inteligente de investir no setor, pois alivia a pressão da demanda sobre as instalações existentes, estendendo o horizonte de atendimento e o custo financeiro e ambiental do desperdício é grande e recai sobre toda a sociedade". Nesse sentido, combater o consumo ineficiente e improdutivo da eletricidade equivale a criar uma reserva de potência num sistema que já existe, dando-lhe condição de atender os novos consumidores no futuro e permitindo às concessionárias postergar novos investimentos em reforço e ampliação.

O programa prevê, que quando da troca e recolhimento da geladeira antiga para desmanche, no processo sejam separados os materiais metálicos, plásticos, vidros e a espuma de poliuretano, utilizada na isolação do produto. Os gases refrigerantes também são recolhidos e tratados, conforme prevê a legislação. Dessa forma, o meio ambiente não é prejudicado com o descarte indevido dos equipamentos e, por outro lado, esses materiais podem ser reutilizados, promovendo a sustentabilidade do processo. Tal desmanche e descartes são fiscalizados pela Aneel que exige certificado de descarte de cada geladeira recolhida e suas respectivas peças.

Para se chegar às famílias que vão trocar geladeira o projeto segue uma metodologia e estudo técnico. Em 2009, 80 mil famílias em 26 cidades do Estado receberam a visita de equipes 
técnicas credenciadas pela Copel para dar seqüência ao programa. Na ocasião da visita, os técnicos fizeram um diagnóstico energético do refrigerador existente no domicílio observando a época da fabricação, estado de conservação, ruído do motor, funcionamento do termostato e condições da borracha de vedação. Durante a visita técnica, também foram entregues três lâmpadas fluorescentes compactas de 15 watts, que iluminam tanto quanto as lâmpadas comuns de 60 watts, mas consumindo quatro vezes menos.

Conforme os entrevistados, nem todos os que participaram do estudo serão contemplados. A partir de um diagnóstico de cada geladeira, se juntou todos os dados por meio de uma metodologia. Este estudo técnico indicou as 12 mil 'piores geladeiras' do Paraná, que serão substituídas. Sendo que a diferença estimada pela empresa entre o consumo atual dos 12 mil refrigeradores velhos e o que será consumido pelos aparelhos novos daria para abastecer mensalmente cerca de 1,7 mil domicílios.

A Copel começou o programa de substituição em 2009 por duas cidades do interior e outras 24 cidades serão atendidas a partir do primeiro semestre de 2010. De acordo com o seu planejamento, a Copel ainda no ano de 2010 desenvolverá uma nova fase do projeto, fase essa que tem como meta a visita a mais 60.000 clientes, com objetivo de distribuir mais 12.000 refrigeradores.

\subsection{Resultados empíricos}

Conforme Tesch (1990), a análise via comparações é o principal recurso intelectual do pesquisador que utiliza os métodos de pesquisa qualitativa. As diferenças e similaridades identificadas na análise do processo contribuíram para ampliar o potencial explicativo do fenômeno estudado e sistematizar o conhecimento do processo logístico reverso em questão. Esta seção tem o objetivo de comparar o preconizado pela literatura revisada com o processo de logística reversa, atualmente implantado pela empresa Copel, conforme apresentado no quadro 1. 
Quadro 1 - Processo de Logística Reversa implantado pela Copel

\begin{tabular}{|c|c|c|}
\hline $\begin{array}{l}\text { Processo de logística } \\
\text { reversa }\end{array}$ & O que preconiza a literatura & Como a Copel faz \\
\hline $\begin{array}{l}\text { Direcionadores: } \\
\text { (Porque realizar?) }\end{array}$ & $\begin{array}{l}\text { - Econômicos: ganhos } \\
\text { diretos, ganhos indiretos; } \\
\text { - Legislativos: direitos do } \\
\text { consumidor, pro- ambiental; } \\
\text { - Cidadania corporativa. }\end{array}$ & $\begin{array}{l}\text { - Atendimento à cláusula do Contrato de Concessão de } \\
\text { Distribuição de Energia Elétrica e à Lei n }{ }^{\circ} 9.991 / 00 \text {. } \\
\text { - Redução ou postergação da necessidade de novos } \\
\text { investimentos. } \\
\text { - Construção de uma imagem corporativa positiva } \\
\text { perante aos stakeholders. }\end{array}$ \\
\hline $\begin{array}{l}\text { Processos nas fases } \\
\text { de retorno. (Como } \\
\text { retornar?) }\end{array}$ & $\begin{array}{l}\text { - Processo direto: reuso, } \\
\text { revenda, redistribuição; } \\
\text { - Processo de } \\
\text { reaproveitamento: reparo, } \\
\text { reforma, remanufatura, } \\
\text { reciclagem, incineração; } \\
\text { - Processos nas etapas } \\
\text { reversas: coleta, inspeção, } \\
\text { seleção, triagem, } \\
\text { recuperação. }\end{array}$ & $\begin{array}{l}\text { - As novas geladeiras que são utilizadas em substituição } \\
\text { às geladeiras antigas são adquiridas pela Copel, por } \\
\text { meio de processo licitatório, realizado pela área de } \\
\text { suprimento da Copel. } \\
\text { - Participam do processo licitatório, fabricantes de } \\
\text { geladeiras e lojas de venda de eletrodomésticos, que } \\
\text { estejam em dia com suas obrigações fiscais junto ao } \\
\text { governo Federal, Estadual e municipal e que possuam } \\
\text { atestados de capacidade técnica na realização do escopo } \\
\text { constante da licitação. } \\
\text { - O processo licitatório compreende a aquisição de: } \\
\text { fornecimento das geladeiras novas, logística de } \\
\text { armazenamento, transporte, entrega ao cliente, } \\
\text { recolhimento das geladeiras usadas e manufatura } \\
\text { reversa. }\end{array}$ \\
\hline $\begin{array}{l}\text { Atores ou agentes no } \\
\text { retorno (Quem } \\
\text { organiza o retorno?) }\end{array}$ & $\begin{array}{l}\text { - Empresas da cadeia direta; } \\
\text { - Empresas especializadas } \\
\text { em logística reversa; } \\
\text { - Intermediários (sucateiros); } \\
\text { - Indústria de reciclagem. }\end{array}$ & $\begin{array}{l}\text { - Todo o processo de logística direta (entrega da nova } \\
\text { geladeira) e reversa (recolhimento da geladeira antiga } \\
\text { para desmanche e descarte) é realizado pela empresa } \\
\text { fornecedora dos refrigeradores, ganhadora da licitação, } \\
\text { ou seja, a mesma empresa responsável pela cadeia } \\
\text { direta do fornecimento e entrega dos novos } \\
\text { refrigeradores. }\end{array}$ \\
\hline $\begin{array}{l}\text { Destino final dos } \\
\text { produtos retornados. }\end{array}$ & $\begin{array}{l}\text { - Retorno ao vendedor; } \\
\text { - Retorno a indústria; } \\
\text { - Venda em mercado } \\
\text { secundário; } \\
\text { - Doação; } \\
\text { - Reparação e consertos; } \\
\text { - Desmanche } \\
\text { (canibalização); } \\
\text { - Remanufatura; } \\
\text { - Reciclagem industrial; } \\
\text { - Disposição Final. }\end{array}$ & $\begin{array}{l}\text { - O programa prevê que durante o desmanche que } \\
\text { sejam separados os materiais metálicos, plásticos, } \\
\text { vidros e a espuma de poliuretano, utilizada na isolação } \\
\text { do produto. } \\
\text { - Os gases refrigerantes também são recolhidos e } \\
\text { tratados, conforme prevê a legislação. } \\
\text { - Tal desmanche e descartes são fiscalizados pela Aneel } \\
\text { que exige certificado de descarte de cada geladeira } \\
\text { recolhida e suas respectivas peças. }\end{array}$ \\
\hline
\end{tabular}

Fonte: Adaptação Leite, (2003)

No quadro 1 foram explicitadas as ações que a empresa Copel executa para a realização do processo logístico reverso. Percebe-se, ao comparar os processos realizados pela empresa com a teoria, que o programa está aderente ao que a literatura preconiza beneficiando-se nos diversos contextos econômico, ambiental e social: seja pela redução do consumo de energia e consequente postergação de investimentos na geração e distribuição de energia; seja pela diminuição da poluição ambiental por meio da estruturação do processo de recolhimento e desmanche dos refrigeradores antigos; ou mesmo pela redução da conta de luz e geração de empregos nos processos de fabricação e logística/manufatura reversa. 


\section{Considerações finais}

Historicamente os investimentos realizados pelas organizações em ações que colaboram com a preservação do meio ambiente têm sido provocados pela regulação ambiental do setor público, recentemente, à indução da regulação tem se somado a iniciativas empresariais visando aliarem-se objetivos ambientais às estratégias competitivas das empresas. Nesse contexto a logística reversa vem ganhando destaque como área de crescente interesse para investimentos empresariais, estudos e ações governamentais.

O presente trabalho procurou identificar o uso da logística reversa como ferramenta estratégica viabilizadora de benefícios diversos nos contextos econômico, ambiental e social. No caso estudado, verificou-se que para a sociedade em geral, os potenciais benefícios de economia gerada por esses programas, que se utilizam de processos de logística reversa, evitam a construção de nova capacidade de geração e propiciam a redução dos subsídios governamentais, proporcionando a liberação de investimentos para outros fins.

No caso específico das concessionárias de energia, como a Copel, estes programas ainda podem ajudar a reduzir os níveis de inadimplência de seus clientes e podem diminuir as perdas por paradas técnicas e os custos com re-ligações. Além disso, as concessionárias podem oferecer a energia que está sendo economizada para outros clientes e, consequentemente, adiando a necessidade de investimentos em ampliação da capacidade dos sistemas de distribuição, além de melhorar o relacionamento com seus clientes.

Conclui-se que a empresa Copel buscou adequar-se a legislação e a realidade ambiental cada vez mais exigente, implementando práticas sustentáveis que se apóiam no planejamento e gestão da logística reversa para proporcionar vantagens competitivas para a organização tanto em termos financeiros, como também fortalecendo sua imagem junto aos clientes e à comunidade em geral ao implementar um projeto que respeita o meio-ambiente e procura um resultado sustentável.

Para estudos futuros recomenda-se o detalhamento das atividades de gestão e atividades operacionais do processo logístico reverso de forma a verificar se as responsabilidades e os papéis de cada agente estão aderentes a teoria. Recomenda-se também a descrição e detalhamento dos indicadores de desempenho específicos utilizados em tais processos logísticos, que colaboram para sua eficiência e para criação de vantagem competitiva. Outra possibilidade de pesquisa a ser explorada é a verificação das interdependências entres os fluxos diretos e reversos no programa em questão.

Se o desenvolvimento de práticas de gestão integradas de cadeias de suprimentos é essencial ao crescimento econômico e ao desenvolvimento regional, o entendimento e o aperfeiçoamento dos processos de logística reversa como viabilizadores de iniciativas como as da Copel, são essenciais 
para o desenvolvimento sustentável.

\begin{abstract}
This study evaluates the planning and management of reverse logistics in the viability of a project to exchange old refrigerators, with low energy efficiency to new refrigerators that cool better consuming less power. In order to monitor the processes of reverse logistics and confront the observed practice with theory, the method used was the exploratory research in the form of case study. Data collection was conducted through two main sources of evidence: Semistructured interviews and document analysis. As a main result it is concluded that the planning and management of reverse logistics processes, are adherents to the theory advocated by the literature, providing competitive advantages for the organization in financial terms, but also strengthening its corporate image with customers and the community to achieve a project that contributes to sustainable development.
\end{abstract}

Key-words: reverse logistics, sustainability, strategy, energy efficiency.

\title{
Referências
}

ANEEL, Agência Nacional de Energia Elétrica. Ações contra o furto e desperdício de energia integram a maioria dos projetos de eficiência. 2009. Disponível em: <http://www.aneel.gov.br/arquivos/PDF/boletim220.htm\#texto3>. Acesso em: 07 jan. 2010.

BALLOU, R. Logística Empresarial: Transporte, administração de materiais e distribuição física. São Paulo, Atlas, 2007.

BARDIN, L. Análise de conteúdo. Lisboa: Edições 70, 1997.

BOWERSOX, D.J.; CLOSS, D.J. Logística Empresarial. São Paulo: Atlas, 2001.

CARROL, A. A three-dimensional conceptual model of corporate performance. Academy of Management Review. Vol. 4, n. 4, p. 497-505, out. 1979.

trosiret

CARTER, C. R.; ELLRAM, L. M. Reverse logistics: A review of the literature and framework for future investigation. International Journal of Business Logistics, 19(1):85-102, 1998.

CHAVES, G. L. D. ; MARTINS, R. S. Diagnóstico da Logística Reversa na Cadeia de Suprimentos de Alimentos Processados no Oeste Paranaense. In: VIII Simpósio de Administração da Produção, Logística e Operações Internacionais, SIMPOI/FGV 2005, São Paulo. Anais do VIII Simpósio de Administração da Produção, Logística e Operações Internacionais, 2005.

CMMAD/Comissão Mundial sobre Meio Ambiente e Desenvolvimento das Nações Unidas. Nosso Futuro Comum. Rio de Janeiro: Editora da Fundação Getulio Vargas, 1991.

COPEL, Companhia Paranaense de Energia. Copel vai trocar 12 mil geladeiras velhas de famílias de baixa renda. 2009. Disponível em:

$<$ http://www.copel.com/hpcopel/root/nivel2.jsp?endereco=/hpcopel/root/pagcopel2.nsf/docs/33BEB5F5B46918790325 7674005DB093>. Acesso em: 07 jan. 2010.

CSCMP, Council of Supply Chain Management Professionals. Glossary of Terms. 2010. Disponível em: $<$ http://cscmp.org/digital/glossary/glossary.asp>. Acesso em: 20 fev. 2010.

FREEMAN, R. E. The politics of stakeholders theory: some future directions. In: Business Ethics Quarterly, v. 4, n. 4, p. 409-422, 1984

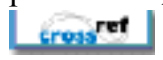

INEE, Instituto Nacional de Eficiência Energética. A eficiência energética e o novo modelo do setor energético. 2001. Disponível em: <www.inee.org.br/down_loads/escos/EE_Novo\%20Modelo.pdf>. Acesso em: 07 jan. 2010. 
JANNUZZI, G. M. Políticas públicas para eficiência energética e energia renovável no novo contexto de mercado. Campinas, FAPESP/Editora Autores Associados, 2000.

JANNUZZI, G. M.; QUEIROZ, G. C.; VENDRUSCULO, E. A. Brazilian domestic refrigerators can be $45 \%$ more energy efficient to save Brazilian consumers significant $\mathbf{R} \$$ on their electricity bill: a detailed life-cycle cost analysis for setting energy efficiency standard in Brazil. Final Report, Climate Technology Initiative, December, 2002.

LAMBERT, D.M. Administração estratégica da logística. São Paulo: Vantine Consultoria, 1998.

LEITE, P. R. Logística reversa: meio ambiente e competitividade. São Paulo: Pearson, 2003.

MALINVERNI, C. Tomra Latasa: A logística da reciclagem. Revista Tecnologística. São Paulo, Ano VIII, $\mathrm{n}^{\circ} 80$. Julho 2002.

ROGERS, D.S.; TIBBEN-LEMBKE, R.S. Going backwards: Reverse Logistics Trends and Practices. University of Nevada, Reno Center for Logistics Management. Reverse Logistics Executive Council. 1998.

SAVITZ, A. W.; WEBER, K. A empresa sustentável: o verdadeiro sucesso é o lucro com responsabilidade social e ambiental. Rio de Janeiro: Elsevier, 2007.

STOCK, J.; SPEH, T.; SHEAR, H. Many happy (product) returns. Harvard Business Review, July:16, 2002.

STRAUSS, A.; CORBIN, J. Pesquisa qualitativa: técnicas e procedimentos para o desenvolvimento de teoria fundamentada. Porto Alegre: Armed, 2008. Parte. I

STROBEL, J. S.; CORAL, E.; SELIG, P. M. Indicadores de sustentabilidade corporativa: uma análise comparativa. In: Encontro Anual da Anpad, 28, Curitiba, 2004, Anais...Curitiba: ANPAD, 2004.

TESCH, R. Types of Qualitative Analysis. In: Qualitative Research, Analysis Types and Software Tools. New York: The Falmer Press, 1990.

WISER, R.; MURRAY, C. International experience with public benefits funds: a focus on renewable energy and energy efficiency, Energy Foundation, China Sustainable Energy Program: 100, 2003.

YIN, R.K. Estudo de Caso: Planejamento e Métodos. Porto Alegre: Bookamn, ed. 3. 2005.

\section{Dados dos autores:}

\section{Nome completo: Frederico Pessanha Gomes}

Filiação institucional: PUCPR

Departamento: Programa de Mestrado e Doutorado em Administração - PPAD

Função ou cargo ocupado: Mestrando

Endereço completo para correspondência (bairro, cidade, estado, país e CEP): Rua Amazonas, 1001 - AP41 - Água Verde - CEP 80610-030 - Curitiba-PR.

Telefones para contato: (41) 3022-5424 / 8863-1892

e-mail:frederico.gomes@uol.com.br

Nome completo: Ubiratã Tortato

Filiação institucional: PUCPR

Departamento: Programa de Mestrado e Doutorado em Administração - PPAD 
Função ou cargo ocupado: Professor

Endereço completo para correspondência (bairro, cidade, estado, país e CEP): Rua Imaculada Conceição, Prado Velho - Curitiba-PR

Telefones para contato: (41) 3271-1476

e-mail: ubirata.tortato@pucbr.br

Recebido para publicação em: 13/10/2010

Aceito para publicação em: 30/11/2010 